\title{
ANTI BACTERIAL EFFECT OF DIFFERENT ADHESIVE ROOT CANAL SEALER
}

\author{
Medhat Taha Elfaramawy* and Shady Ali Hussein*
}

\begin{abstract}
Aim of the study: To compare the antibacterial effect of ActivGPsealer (Glass Ionomer based) (Brasseler, Savannah, USA) versus AD seal (Resin based sealer) (META, Chungcheongbukdo, Korea) and AH 26 sealer (Resin based sealer) (Densply, USA) against E-faecalis using agar diffusion method. Samples were classified into 3 groups according to the material used Group 1: Activ GP sealer, Group 2: AD seal and group 3; AH 26. Each group was classified into three subgroups according to the observation periods ( 1 day, 3 days and 7 days). Each group consisted of 7 agar plates implanted with E-faecalis strain. 3 holes were created in each agar plate each hole contained one tested material. The results showed that the AH Plus exhibited the largest inhibitory zone followed by Activ GP which exhibited the anti bacterial activity only after 3 days while $\mathrm{AD}$ seal exhibited no antibacterial activity. It has been concluded that the antimicrobial activity of AH Plus was greater than Activ GP, which were more efficient in bacterial inhibition than AD seal.
\end{abstract}

\section{INTRODUCTION}

The main goal of root canal treatment is the elimination of the root canal bacteria, the residual bacteria after cleaning and shaping procedures obligates to have a root canal obturating materials and sealers with antibacterial properties. The antimicrobial activity of root canal sealers gives them superiority especially in cases of recurrent infections. Many in-vitro studies investigated the antibacterial activity of many sealers with various methods ${ }^{(1)}$. Agar diffusion test (ADT) is one of the most commonly used methods for evaluation of the antibacterial activity. E-faecalis is such a microbial species which was found as a major cause of persistent root canal infection and was detected in the peri-apical lesions ${ }^{(2-5)}$ also E-faecalis has the ability to invade into dentinal tubules and resist most of the chemicals used in root canal treatment ${ }^{(6)}$. In this research the antibacterial effect of three different sealers was evaluated against E-faecalis.

\footnotetext{
* Lecturer of Endodontics. Faculty of Dentistry. Ain Shams Univ.
} 


\section{MATERIALS AND METHODS}

\section{I- Materials}

In this study, the following materials were used:

\section{a) Bacterial isolates:}

A total of 7Enterococcus faecalis isolates were included in this study.

\section{b) Substances:}

1- Activ GP sealer(glassionomer based sealer).

2- AD Seal (Resin based sealer).

3- AH Plus (Resin based sealer).

\section{c) Media:}

The following media were used in this study:

\section{Brain-Heart Infusion Broth:}

This medium was used to prepare the suspension of Enterococcus faecalis.

\section{Brain-Heart Infusion Agar:}

This medium was used to test the effect of the different substances on the growth of Enterococcus Faecalis using the diffusion agar method.

\section{Methods:}

\section{d) Preparation of Brain-Heart Infusion Broth:}

Thirty seven grams of the medium were suspended in one liter of distilled water. Heating with frequent agitation ensured good mixing and dissolution. The suspension was then boiled for one minute until complete dissolution. It was later dispensed into appropriate containers and sterilized at $121^{\circ} \mathrm{C}$ for 15 minutes. The prepared medium was stored at $2-8^{\circ} \mathrm{C}$. For best results, the medium was used on the same day.

\section{e) Preparation of Brain-Heart Infusion Agar:}

Fifteen grams of agar powder were added to 1 liter BHI broth and then heated to dissolve agar before dispensing into appropriate containers. Autoclaving was then performed for $15 \mathrm{~min}$ at $121^{\circ} \mathrm{C}$ to ensure adequate sterilization. The mixture was then poured into Petri dishes nd left to cool andsolidify.

\section{f) Preparation of Enterococcus Faecalis Suspen- sion:}

A sterile swab was used to transfer bacterial growth from the primary culture into the BHI broth bottle and mixed well to form a homogenous suspension.

\section{g) Classification of samples:}

21 samples were classified according to the tested material into 3 groups

Group 1: consisted of 7 holes filled with Activ GP

Group 2: consisted of 7 holes filled with AD Seal Group 3: consisted of 7 holes filled with AH Plus

Each group was further classified into 3 subgroups according to the observation period

Subgroup A: One day

Subgroup b: Three days

Subgroup c: Seven days

\section{h) Implantation of the E-faecalis in the agar plates:}

A sterile cotton swab was dipped into the suspension and excess fluid was removed by turning the swab against the insidewall of the tube. The inoculum was evenly spread over the entire surface of dry BHI agar plates by swabbing in three different directions.

\section{i) Mixing and application of the tested substances:}

Three holes of $4 \mathrm{~mm}$ diameter were made on the agar surface by a metal punch leaving about 10-15 $\mathrm{mm}$ away from the edge of the petri dish, and these holes were separated from each other by a distance not less than $20 \mathrm{~mm}$ to avoid overlapping zones of inhibition. 
Each hole contained one of the tested materials and marked as follow:

Hole number I for Aciv GP, hole number II for AD Seal and hole number III for AH Plus:

All the agar plates were incubated at $37^{\circ} \mathrm{C}$ in aerobic conditions for the required observation periods.

\section{j) Method of evaluation ${ }^{(7)}$;}

After one day observation period the area of microbial growth inhibition (lack of bacterial colonization) around the holes were measured at the largest diameter with a poly gauge millimeter ruler.

The agar plates were then re-incubated to take the measurements of the inhibitory zones after 3 days and then after 7 days.

\section{k) Statistical analysis}

Data were analyzed by SPSS software (version 16.0, SPSS, Chicago, IL, USA). Data in each group were compared by the ANOVA and KruskalWallis tests. Also the Dunnett's test was performed to compare the results between two groups. The level of significance was set at 0.05 .

\section{RESULTS}

\section{A-Group one (ActivGP):}

After one day observation period there was no area of inhibition. After 3 days it showed area of inhibitory zone of $4 \mathrm{~mm}$. which was not changed after 7 days.

\section{B-Group two AD Seal:}

Showed no area of inhibition of bacterial growth among the three observation periods..

\section{C-Group three AH Plus:}

The average of the diameter of the inhibitory zone was $10 \mathrm{~mm}$. after one day, which was not changed after 3 or 7 days.
TABLE (1) The diameter of the inhibitory zones of tested materials .

\begin{tabular}{|l|l|l|l|l|}
\hline $\begin{array}{l}\text { Subgroup } \\
\text { Group }\end{array}$ & ActivGp & AD Seal & AH Plus & P value \\
\hline One day & $0 \mathrm{~mm}$ & $0 \mathrm{~mm}$ & $10 \mathrm{~mm}$ & $<0.0001$ \\
\hline 3 days & $4 \mathrm{~mm}$ & $0 \mathrm{~mm}$ & $10 \mathrm{~mm}$ & $<0.0001$ \\
\hline 7 days & $4 \mathrm{~mm}$ & $0 \mathrm{~mm}$ & $10 \mathrm{~mm}$ & $<0.0001$ \\
\hline
\end{tabular}

$P \leq 0.05$ is considered significant.

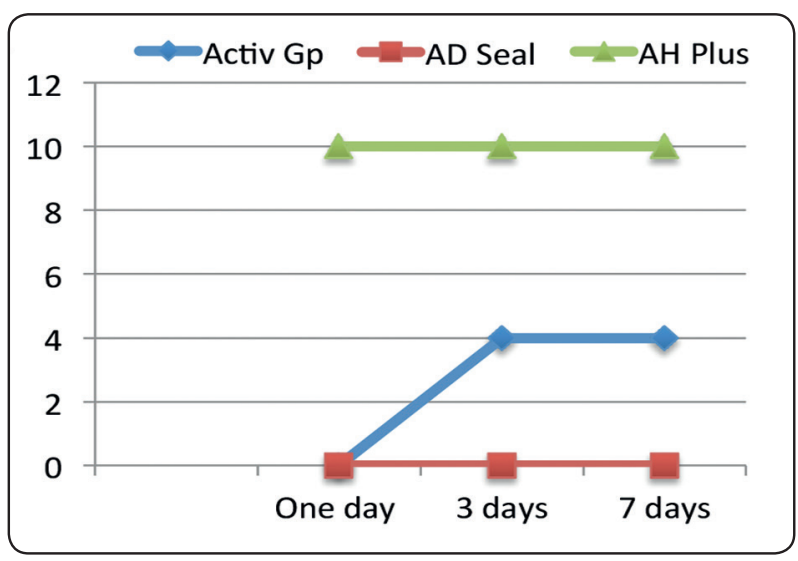

Fig. (1) Diagram showing the diameter of the inhibitory zone of the tested materials.

\section{DISCUSSION}

Persistence of bacteria after endodontic treatment may cause failure of the treatment. E-faecalis is considered the most resistant species that can survive in the root canal system even after the endodontic treatment ${ }^{(7)}$

It is advantageous for the endodontic sealers to have the property of bactericidal or at least the bacteriostatic activity. May help to eliminate the residual bacteria that was not eliminated during the chemo-mechanical preparation of the root canal system which can improve the success rate of the endodontic treatment ${ }^{(8,9)}$. This study was conducted to evaluate the antibacterial activity of 
glass ionomer based sealer compared to two resin based sealers using agar diffusion method (ADT). ADT depends on the solubility and physical properties of the antimicrobial component of the sealer ${ }^{(10)}$. The results were based on the comparison of the effect of duration on the anti bacterial activity of each tested sealer and comparing the anti bacterial property of different sealers in the same observation period. On comparing the effect of time interval of the antibacterial activity of Activ GP sealer, it exhibited no anti bacterial activity at one-day observation period. However, there was a significant increase in the zone of inhibition by time especially at 3 days interval, which was not changed after 7 days interval. This findings were comparable to Anumulaetal. ${ }^{(9)}$ who stated that glass ionomer based sealer showed anti bacterial activity which may be related to the release of fluoride and the low $\mathrm{pH}$ in addition to the release of zinc ions. Another explanation may be related to the solubility of glass ionomer, which increased after 3 days and so increased its anti bacterial activity. For AD seal sealer it exhibited no anti-bacterial activity which was not changed by time. These findings was in agreement with Wainsteinetal. (7) and Goldberg et al. (11) This may be related to its lack of solubility and diffuse-ability of this sealer. For AH Plus it exhibited significantly larger zone of inhibition than the Activ GP and AD Seal, This zone of inhibition was not changed by time. This short acting potent and diffusible anti-bacterial activity of AH Plus within the first 24 hours was explained by Pizzo et al., ${ }^{(8)}$ as it contains an antimicrobial component which is capable of diffusing into liquid media and exhibit strong bactericidal activity. These findings were in disagreement withMickeletal. ${ }^{(12)}$

\section{CONCLUSION}

It has been concluded that the antimicrobial activity of AH Plus was greater than Activ GP, which were more efficient in bacterial inhibition than AD seal.

\section{REFERENCES}

1. Alshwaimi E., Bogari D., Ajaj R., Alshahrani S, Almas K. and abdulmajeed. In Vitro Antimicrobial Effectiveness of Root Canal Sealers against Enterococcus faecalis: A Systematic Review. 2016;42:1588-97.

2. Rocas IN, Siqueira JF Jr. Characterization of microbiota of root canal-treated teeth with posttreatment disease. J ClinMicrobiol 2012;50:1721-4.

3. Gomes BP, Pinheiro ET, Jacinto RC, et al. Microbial analysis of canals of root-filled teeth with periapical lesions using polymerase chain reaction. J Endod 2008;34:537-40.

4. Sakamoto M, Siqueira JF Jr, Roc as IN, Benno Y. Molecular analysis of the root canal microbiota associated with endodontic treatment failures. Oral MicrobiolImmunol 2008;23:275-81.

5. Siqueira JF Jr, Roc ${ }_{3}$ as IN. Uncultivated phylotypesand newly named species associated with primary and persistent endodontic infections. J ClinMicrobiol 2005;43:3314-9.

6. Sundqvist G, Figdor D, Persson S, Sjogren U. Microbiologic analysis of teeth with failed endodontic treatment and the outcome of conservative re-treatment. Oral Surg Oral Med Oral Pathol Oral RadiolEndod 1998;85:86-93.

7. Wainstein M, Morgental RD, Waltrick SB, et al. In vitro antibacterial activity of a silicone-based endodontic sealer and two conventional sealers. Braz Oral Res 2016;30:e18

8. Pizzo G, Giammanco GM, Cumbo E, et al. In vitro antibacterial activity of endodontic sealers. J Dent 2006; 34:35-40.

9. Anumula L, Kumar S, Kumar VS, et al. An assessment of antibacterial activity of four endodontic sealers on enterococcus faecalis by a direct contact test: an in vitro study. ISRN Dent 2012;2012:989781.

10. Shakya V.K., Gupta P. and Tikko A.P. An in-vitro evaluation of antimicrobial efficacy and flow characteristics For AH Plus, MTA Fillapex, CRCS and Gutta flow. J.Clin. andDiag.R 2016;10:104-08

11. Slutzky-Goldberg I, Slutzky H, Solomonov M, et al. Antibacterial properties of four endodontic sealers. J Endod 2008;34:735-8.

12. Mickel AK, Nguyen TH, Chogle S. Antimicrobial activity of endodontic sealers on Enterococcus faecalis. J Endod 2003;29:257-8. 